\title{
Removal of mineral oil from engineers' overalls
}

\author{
DERMOD P. G. PAISLEY and J. T. McCULLINS \\ Ministry of Health and Social Services, Belfast and Department of Industrial \\ and Forensic Science, Belfast, Northern Ireland
}

During the past year a great deal of attention has been given to the question of contamination of working clothes by mineral oils, and some firms have introduced schemes aimed at reducing the skin hazard from this cause. The basis of all the arrangements known to us is to ensure that all engineering overalls are laundered weekly. Some firms supply each of the workers with two pairs of overalls and have arrangements with laundry companies whereby soiled overalls are collected for laundering once weekly and freshly laundered overalls are delivered. Other firms do not supply the overalls but make them available to the workers at low cost. Some firms bear the cost of the laundering, in others this cost is borne by the worker, but no doubt where arrangements have been made for regular laundering of bulk quantities the cost of this service to the individual is less than it otherwise would be. In yet other firms a small sum of money is included in the weekly pay packet to defray the cost of laundering overalls, the worker making his own arrangements for this.

Observation of the state of many of the overalls in one factory where the last mentioned arrangements operate led to doubts about the application of the money supplied to the workers for laundering overalls. A suit of overalls was obtained from one worker on a Wednesday. We accepted his statement that his overalls are laundered weekly and that the suit in question had been brought into use 'clean' on the Monday. The $16 \mathrm{sq} \mathrm{ft}\left(1.48 \mathrm{~m}^{2}\right)$ of material which comprised the legs and waist pieces were submitted to solvent extraction and yielded over $3 \mathrm{oz}(0.09 \mathrm{~kg})$ of a viscous dark brown mineral oil which contained fine silica particles and minute metal turnings from which it was freed by filtration. This oil was saturated aliphatic in nature and had a strong ultraviolet fluorescence; there can be no doubt that it originated from lubricants and cooling oils used in the metal working process.
This finding posed several questions:

1. Where laundering of overalls is left to the worker is it likely that this will be done regularly and efficiently?

2. Is once weekly laundering sufficient or should the interval be shorter?

3. How efficient is wet laundering of overalls in removing mineral oil contamination?

To resolve these questions 12 pieces of a cotton fabric known as blue drill, each $1 \mathrm{ft}$ square $\left(0.09 \mathrm{~m}^{2}\right)$, were obtained from a local overall manufacturer and washed in anionic detergent three times and well rinsed in order to free the material from both synthetic and farinaceous sizes and dressings. They were then air dried down to an approximate normal moisture regain of $7 \%$ and thereafter six were inoculated with a light grade of engineering lubricant, corresponding approximately to S.A.E. 10 and six were inoculated with a heavy grade corresponding to S.A.E. 30. Application took the form of total immersion in a 1 to $6 \mathrm{vol} / \mathrm{vol}$ solution of the lubricant in petroleum ether. Air drying was allowed to proceed together with drip drying and on an average it was found that $6.4 \mathrm{~g}$ (range 6.19 to 6.72) of the S.A.E. 10 oil and $6 \cdot 7 \mathrm{~g}$ (range $6 \cdot 2$ to $7 \cdot 1$ ) of the S.A.E. 30 oil were absorbed by the 1 -sq $\mathrm{ft}$ samples of the blue drill material.

After approximately 24 hours air drying, when the test pieces no longer smelled of petroleum ether, they were wet laundered in hot soft water using a well-known brand of anionic detergent which contained soda-ash, metasilicate and carboxymethyl cellulose as manufacturer's additives. This detergent formula is similar to those recommended by the British Launderers' Research Association.

After rinsing and normal drying the test pieces were exhaustively extracted and it was found that the S.A.E. 10 test pieces still contained $3.3 \mathrm{~g}$ (range 2.9 to 3.59 ) of oily contaminant and the S.A.E. 30 pieces $3.9 \mathrm{~g}$ (range 3.49 to 4.31 ) 
It is clear from this work that thorough controlled and supervised washing by the wet method will not remove more than $50 \%$ of the original contaminants in soiled engineers' overalls. Indeed these figures may be on the liberal side as these experiments concerned contamination by clean solid-free oils. In ordinary practice the contaminants will be more tenacious due to the presence of finely divided particulate matter and will not be as easily washed out as the clean oils used in the experiments.

\section{Conclusions}

1. If engineering lubricants cannot be effectively removed from overalls by wet washing, then a supposedly clean garment worn by a worker at the beginning of each week will contain oil-contaminated capillaries in the fabric before he starts his work. Such fabrics may appear clean, and may even feel softer due to the presence of the oil, but this fabric condition is more rapidly recontaminated than a truly oil-free garment due to the capillary effect.

2. Since contamination of garments in engineering factories is always with oil associated with particulate matter, the residual oil which cannot be washed out will tend to make the abrasive particles more tenacious with the result that the hazard of skin disease by mechanical irritation is always present.

3. The weekly laundering of overalls to remove mineral oil contamination induces a false sense of security.

4. The only sure way of freeing overalls from oil and abrasive particles is by solvent extraction. Using perchlorethylene our laboratory work reveals that the cloth particles are completely free from oil at the end of the extraction cycle and this leads to the conclusion that this type of dry cleaning tends to be exhaustive as far as oil extraction is concerned.

Received for publication July 14, 1969.

\title{
Histamine in cereal dusts
}

\author{
P. J. NICHOLLS \\ University of Wales Institute of Science and Technology, Cardiff
}

\begin{abstract}
Nicholls, P. J. (1970). Brit. J. industr. Med., 27, 179-180. Histamine in cereal dusts. It has been found that workers exposed to cereal grain dusts may experience acute mild respiratory distress. An attempt has been made to explain this observation by examining the pharmacological activity of aqueous extracts of several cereal dusts from the holds of cargo ships. Histamine, but no other active agent, was found in the samples. It is unlikely that the concentration of histamine in these dusts is sufficient to cause respiratory distress in dockers unloading cereal grain cargoes.
\end{abstract}

Dockers unloading cargoes of cereal grain are often exposed to high concentrations of airborne cereal dust. It has been observed that several of these dusts can cause acute mild respiratory distress in the dockers and that inhalation of wheat dust produces a significant decrease in forced expiratory volume (Gandevia and Ritchie, 1966). It therefore appeared important to investigate the possibility that such effects are produced by a pharmacologically active agent in the dusts. 